然

Global Journals Inc

(8)

\title{
Smart Airport: A Review on Future of the Airport Operation
}

\author{
By Aruna Rajapaksha \& Dr. Nisha Jayasuriya
}

Abstract-Smart Airport concept is the future of Airport operation and it may dramatically change the industry towards modern technology adaptation. This study mainly focuses on the Smart airport applications in to passenger terminal process. Literature scattered on different sources have been summarised to explain the features of smart airport with practical cases in global context. Empirical indications on implementation of the smart airport applications discussed based on practical implications of airport operations. Special attention given to the cases of the best performing major airports in Asia, Middle East \& Europe. This study contribute to the field of academia and industry by identifying the advantages of smart airport implementation under the key areas of Aviation Security, Passenger Convenience, Operational Efficiency and Optimizing Limited resources. Further implantation methodology under passenger, baggage handling \& regulatory controls have been discussed in this paper. Finally key challenges in implementation of the smart airport concept has been addressed and concludes with empirical justifications highlighting future research priorities on implementing the concept.

Keywords: airport operation, aviation security, capacity crunch, operational efficiency, passenger terminal process, practical implications, smart airport, technology adaptation.

GJMBR-A Classification: JEL Code: M19

Strictly as per the compliance and regulations of:

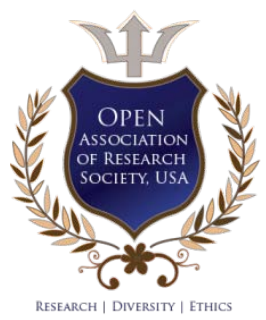

(C) 2020. Aruna Rajapaksha \& Dr. Nisha Jayasuriya. This is a research/review paper, distributed under the terms of the Creative Commons Attribution-Noncommercial 3.0 Unported License http://creativecommons.org/licenses/by-nc/3.0/), permitting all noncommercial use, distribution, and reproduction in any medium, provided the original work is properly cited. 


\title{
Smart Airport: A Review on Future of the Airport Operation
}

\author{
Aruna Rajapaksha ${ }^{\alpha} \&$ Dr. Nisha Jayasuriya ${ }^{\sigma}$
}

Abstract- Smart Airport concept is the future of Airport operation and it may dramatically change the industry towards modern technology adaptation. This study mainly focuses on the Smart airport applications in to passenger terminal process. Literature scattered on different sources have been summarised to explain the features of smart airport with practical cases in global context. Empirical indications on implementation of the smart airport applications discussed based on practical implications of airport operations. Special attention given to the cases of the best performing major airports in Asia, Middle East \& Europe. This study contribute to the field of academia and industry by identifying the advantages of smart airport implementation under the key areas of Aviation Security, Passenger Convenience, Operational Efficiency and Optimizing Limited resources. Further implantation methodology under passenger, baggage handling \& regulatory controls have been discussed in this paper. Finally key challenges in implementation of the smart airport concept has been addressed and concludes with empirical justifications highlighting future research priorities on implementing the concept.

Keywords: airport operation, aviation security, capacity crunch, operational efficiency, passenger terminal process, practical implications, smart airport, technology adaptation.

\section{InTRODUCTION}

$\mathrm{M}$ odern aviation industry is developing very fast. The rapid growth of passenger volumes alarming to have advanced technology features for design of future airports to improve efficacy levels as well as to utilise limited infrastructure effectively (Medvedev, Alomar, \& Augustyn, 2017). Airports Council International $(\mathrm{ACl})$ statistics show 8.8 billion passenger traffic in the year 2018, which is 6\% growth compared to the previous year(ACl World, 2019). As per the passenger forecast published by the International Air Transport Association (IATA), the Asia Pacific region creates the largest passenger volume up to the year 2035 and predicting almost $50 \%$ of new passengers to be originated. As per the estimates up to 2035, new passengers 1.8 billion will travel from \& within the Asian Pacific region with a $4.7 \%$ annual growth rate with 3.1 billion passengers (IATA, 2019).

Author $\alpha$ : Doctor Candidate Faculty of Commerce \& Management Studies, University of Kelaniya, Sri Lanka. e-mail: aruna.am@airport.lk Author o: Senior Lecturer SLIT Business School, Sri Lanka Institute of Information Technology, Sri Lanka. e-mail: nisha.j@sliit.lk
The existing rapid growth of passenger volumes has already created a pressure on airport operators to re-consider the ability of the available infrastructure and focus on terminal capacity enhancement, process improvements, new revenue models and offer worldclass services to attract global passengers whilst controlling physical \& cyber security. Critical airport terminal process limitations are the efficiency of check-in process, integrated systems, CUTE (Common User Terminal Equipment), "Agent-facing" systems which shared with regulatory agencies and concessionaries (Sabatová, Galanda, Adamčík, Jezný, \& Šulej, 2016).

Main airports in Europe, USA, Middle East and Asia are well equipped with modern technology and ready for digital transformation. They use cutting-edge technology and innovations in Information Technology \& Telecommunication (IT\&T). However, some of the airports in developing countries are not par with digital transformation and struggle with traditional airport infrastructure \& processes.

The level of technology adaptation of an airport can be named as the digital maturity and airport technology adaptation can be divided into four stages such as Airport 1.0, 2.0, 3.0 and 4.0(Nau \& Benoit, 2017). This concept is presented in Figure 1. 
AIRPORT 4.0

1. Generate ancillary revenues

2. Passenger experience

\section{AIRP0RT 3.0}

1. Capacity raise

2. Passenger experlence

3. Cost reduction \& process improvement

\section{AIRPORT 2.0}

1. Cost reduction \& process improvement

2. Passenger experience

\section{AIRPORT 1.0}

Figure 1: Level of Technology Adaptation in Airports (Nau \& Benoit, 2017)

According to the above classification, the traditional airports which are with manual processes and basic IT solutions are known as Airport 1.0. The next level, Airport 2.0 is known as early adaptors to the digital technology into airport operations and partial selfservice facilities available such as Wi-Fi technology \& check-in process. When all level of passenger services of an airport equipped to provide full self-service, it named as Airport 3.0.In those airports, operational controls are automated whilst predictive and mobility solutions heavily used in passenger Terminal as well as in the airside.

The emerging technologies lead the airport industry towards Smart airports (NATS, 2019). Latest smart technology airport solutions practice smart gates, check-in, baggage monitoring, facial recognition, biometric identifications, airport terminal navigation through mobile devices, IP based security, data analytics, data mining to study passenger behaviour, Al adaptations and many other operational quality enhancements.

As Smart Airport is still a developing concept, a limited literature available on specific scopes under the smart airport operations and lack of general discussions on advantages, methods of practical implementation and challenges with special attention on terminal operations. There for the purpose of this paper is to find out above details with rational justifications. The author has used the deductive approach. Literature review explains research findings, theoretical models and empirical evidence relevant to the smart airport concept. Number of real case studies disused with practical examples on international context to justify the findings of the paper.

\section{il. Literature Review}

\section{a) Smart Airport}

As a result of fourth industrial revolution the Smart airport concept have been evolving all over the world eliminating the drawbacks of the conventional airport system. According to Bouyakoub, Belkhir, Guebli, \& Bouyakoub, (2017) Airport 4.0 is a concept which leverages big data and open data to enhance its own innovation. In those airports, operators create value for operational efficiencies from collecting data with realtime passenger flow whilst analysis passenger profile.

IOT provide facility to interact with different smart devices and this approach generate many new applications in large variety of fields such as environment, health, smart cities and industry (Bouyakoub et al., 2017).

The concept of Smart Airport which is based on Humanism and $\mathrm{O} 2 \mathrm{O}$ mode. Humanism address the passengers and civil aviation industry employees. It provides satisfaction for passengers while providing a pleasant and efficient working environment for employees. While $\mathrm{O} 2 \mathrm{O}$ mode construct an effective combination of an offline airport and online airport. In this $\mathrm{O} 2 \mathrm{O}$ mode offline one provide a personalised solution for passengers while online one provide all the digital information and inquiring services for passengers' need (Qi \& Pan, 2018). 


\section{b) Smart Airport Definitions}

The definition for the 4th evolution of the airport which is known as Airport 4.0 is still being evolved. There are diverse definitions available in different literature for the airport 4.0 or the synonym called as smart airport. The definition for smart airport is related to the definition of smart city. Smart cities apply technology for urban lives in order to create more convenient and sustainable environment. Smart Airport is a sub system of this smart city. In this system, urban life and aircraft movements are connected. Information are readily exchange among urban transportation management, air traffic control and air lines. Via this connectivity the optimization of individual processes and airport operation as well as customer satisfaction are aimed to achieve (Nagy \& Csiszár, 2016). The figure 2 indicates the Smart Airport operations within a Smart City concept.

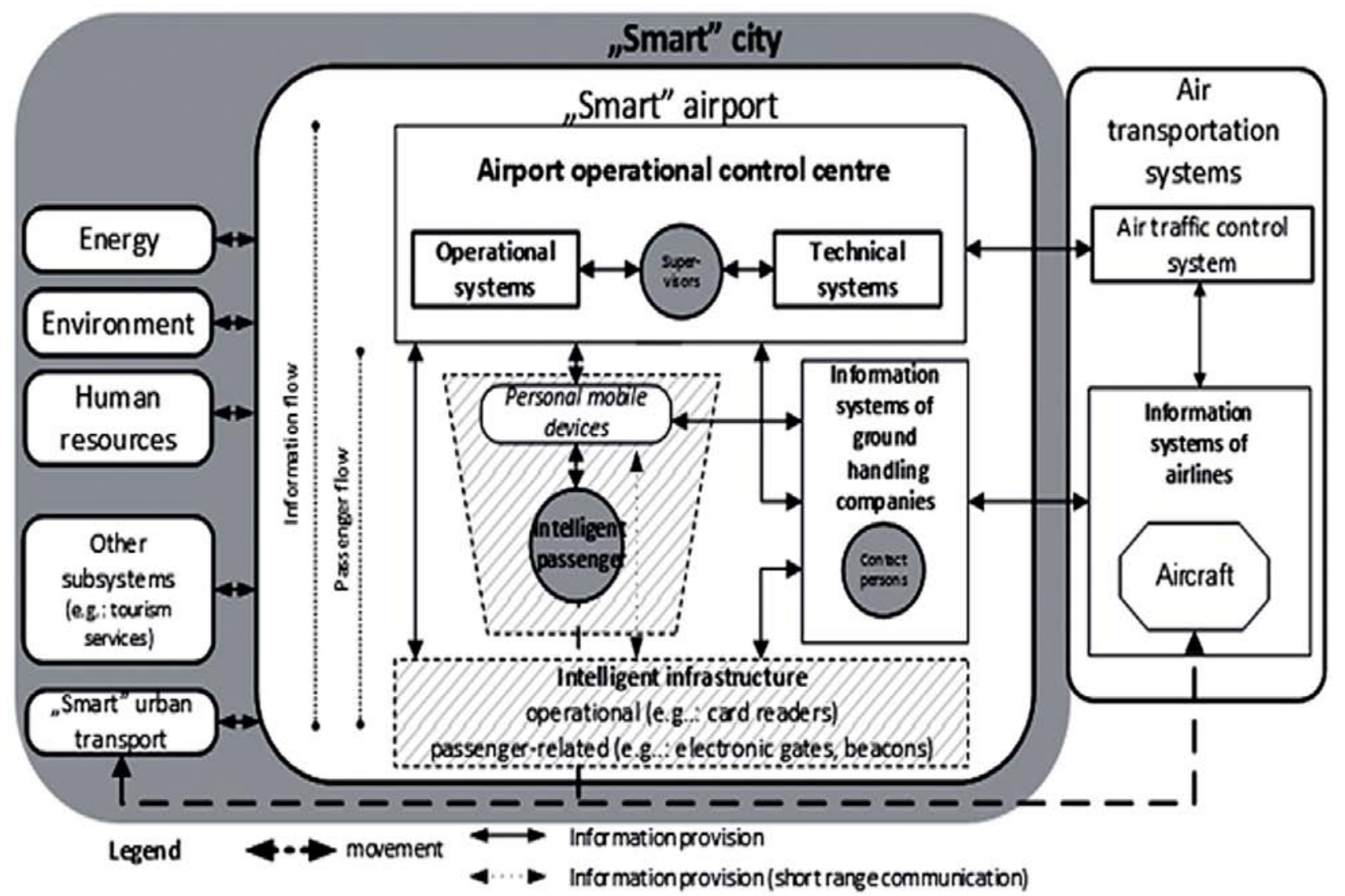

Figure 2: Model of "smart" airport in the concept of "smart" city.

Source: Nagy \& Csiszár, (2016)

According to Qi \& Pan, (2018) the concept of Smart airport is tend to achieved a 'man machine integration' by resetting the service process based on IoT, mobile network and big data. Furthermore, Almashari et al., (2018) explained it as an airport solution which enables controlling and monitoring many systems from a remote area unlike in the conventional airports. This provides safer environment for passengers and workers while any fault occurred can be handled immediately.

\section{c) Advantages of Smart Airport}

\section{i. Aviation Security}

Aviation security requirements are mandatory compliances to ensure safer journey to passengers, aircraft as well as to all other airport users. Smart Airports are improving the aviation security standards with modern technology as per the regulatory requirements and reducing passenger inconvenience. Security screening processes in an airport spend considerable time with unpleasant experience \& making unsatisfactory passenger. It is a challenging task to ensure the flight security. Internet of things (IOT) is use as smart application to mobilize, sensing and processing tasks to authenticate passengers together with RFID to offer advanced security service (Jalali \& Zeinali, 2018).

Munich, one of the best European airports has introduced state-of-the-art CT scanner to the passenger terminal which is capable to find solid and liquid explosives. Passengers not required to take out laptops, smart phones and any permitted liquid from their baggage to declare and they can easily process through the scanner for screening requirements (Munich 
Airport, 2019). To face the challenge of rapid growth of passengers may need solutions in addition to the aircraft capacity increase and airport expansions. It is required to have further integrative smart technological developments in airports. Use of Biometrics is another key IT application of Smart Airports to secure personal identification at the passenger security, check-in, border control, \&boarding at the airport(ACI World, 2005).Smart airport provides safer environment for both passengers and workers and if any security fault occurred can be handled immediately with integration of loT.

\section{ii. Passenger convenience}

Passengers expect their convenience throughout the terminal formalities without any harassment to the journey. Travellers of a smart airport do not need to wait long period of time as at a conventional airport. Sensors connected to IoT to provide information about shortest line, parking space and self-checking luggage (Almashari et al., 2018).

Changi Airport in Singapore, crowned as the best airport for the 7th consecutive year by skytrax World Airport Awards (Skytrax, 2019), introduced automated baggage drop machines for their terminal-4 with passenger facial recognition technology. There is no requirement for manual identity checks by security staff as the entire departure screening process automated by allowing flexible, secured and convenience departure process for passengers (Changiairport.com, 2019). Incheon Airport in South Korea already introduced "Airstar" robots to the terminal process for passenger ushering. These robots placed in passenger congesting areas such as departure lobby, duty-free stores and baggage belts at the arrival area. Further they are improving passenger convenience and smart experience services for airport users by guiding, transporting, vehicle parking, self-driving vehicles and indoor terminal location finding technology (Incheon Airport, 2019).

\section{iii. Operational efficiency}

Data collection of passengers is more important to improve operational efficiency. Big data analysis is the most beneficial advantage of a Smart airport. Identify passenger behaviour, more revenue generation, trace passenger gathering locations, calculate waiting time average of a passenger and all other personal behaviours of passengers can determine based on the smart data processing (Al Nuaimi, Al Neyadi, Mohamed, \& Al-Jaroodi, 2015).

Modern Airport operators' keen on sensing and network infrastructure, data management infrastructure, data analytics, and Artificial Intelligence and Machine Learning capacity to upgrade operational efficiency level of the airport. Changi Airport has already implement Al and ML-enabled applications for various functions that can sense better, analyse better, predict better and improve the operational efficiency(Lee \& Miller, 2019).
Incheon Airport has improved operational efficiency with smart technology by utilizing real time data. On-time performance and passenger convenience enhanced by real-time monitoring of flight delays, in-flight waiting times, and passenger terminal process. Also strictly control operational delays with digital display boards and intelligent CCTVs. Further operational dashboards automatically update \& alert on required level of resources and performance levels through big data analysis (Incheon Airport, 2019).

\section{iv. Optimising limited resources}

Airports need to optimize limited terminal space whilst ensuring more space for commercial activities, to get reduced airline operating costs can use modern technology adaptation. Throughout terminal process the passenger comfort and smooth processes are the most priority needs(Castillo-Manzano \& López-Valpuesta, 2013). There are two methods to reduce passenger waiting time in the terminal building as increasing terminal passenger service resources and allocate terminal resources based on passenger flow fluctuations in different times(Cheng, Zhang, \& Guo, 2012). It is possible to reduce operational costs of the terminal and improve the operational efficiency by implementing above solutions in a proper methodology.

Smart airports concept is the best solution for optimum utilization of limited airport resources including terminal, airside and landside. Smart airports can introduce IOT based real-time data systems to predict peak time at the terminal and propose the best resource shifting arrangements on $\mathrm{Al}$ analysis. Also manpower allocation can manage effectively and reduce staff engagements in automated passenger processes. Robots technology, personalized mobile phone directives, smart information panels and Airport Collaborative Decision Making (A-CDM) systems can optimize limited resources available. A-CDM system introduced by Incheon Airport in 2017 to integrate realtime data with ATC Tower \&Apron Control Tower. Improved the response capabilities with departure times and runway queues in advance by A-CDM system (Incheon Airport, 2019). Further, smart technology helps in reducing energy use by handling lighting and air conditioning systems based on a demand at a certain timing. This helps to reduce cost related to energy consumption (Almashari et al., 2018).

\section{ili. Application in to Smart Airport Operation}

Airport Management is the most responsible and critical task in airport operations with limited resources, dealing with internal \& external agencies, maintain on-time service delivery, maintain security of passengers \& visitors, safe aerodrome operation whilst ensuring regulatory compliances. Airport terminal operations can mainly divide in to passenger service, 
baggage handling \& regulatory clearance. The impact of smart technology provide various solutions to overcome airport challenges due to increasing passenger flow during peak hours (Mohamed, Gomaa, \& El-Sherif, 2018). Smart airport applications can further elaborate based on above key components as follows;

\section{a) Smart Check-in}

Passenger can use several methods for checkin by using the web, mobile phones, personalised methods and computer-based kiosks are limiting the human involvement by ground handling staff and reduce the cost component and human error (Wittmer, 2011). Earlier some of the airlines were maintaining exclusive kiosks only for their passengers. SMART airports interlinked all severs of operating airlines and passengers can check-in through any shared kiosk placed at the terminal. This is a better solution for limited terminal space available whilst reducing cost engagement instead of different counter allocation for individual airlines.

\section{b) Self-boarding}

The main expectation of smart airport technology is to offer more efficient and convenient travel experience by introducing interconnected digitalized systems and processes (Mohamed et al., 2018). Boarding process is one of the most unpleasant and tension experience to the passenger due to number of security screenings and manual processes. Therefore it is required to empower passengers to have their own boarding process with flexibility. Boarding card scanning machines place at the gates to self-scan the boarding pass printed by the self-check-in counter. Passengers empowered to board into the aircraft without human checking process but using the latest RFID scanning methodology. Boarding gates open to the passenger based on the data scanned in the boarding pass and passengers can get into the aircraft. Human involvement only for the supervisory process by the ground handling staff.

\section{c) Indoor navigation}

Mobile devise applications offer personalized information on their flight times, airport locations, and other needs help to usher passengers on time to the aircraft. Navigation from and to the airport and all other related facility locations within the terminal can be included in to the personal devises. Indoor mapping within the terminal building with processing speeds will give required alerts to the passenger (Mantouka, Barmpounakis, Milioti, \& Vlahogianni, 2019). Passengers who are using the airport for the first time may need to usher for airport formalities and later to the boring gates. Google indoor maps or airport app can help passengers to show the airport locations conveniently. SMART apps direct passengers to complete their airport formalities perfectly without the assistance of ground handling staff. This may reduce the necessity of airport terminal signage.

\section{d) Biometric services}

Most of the modern airports are implementing automated personal identification systems in to the vulnerable controlling points based on physiological characteristics. Facial recognition, fingerprints, hand geometry, handwriting, voice, retinal and vein are identified as more tractable biometric features (Sharif, Raza, Shah, Yasmin, \& Fernandes, 2019). These services creating passenger convenience throughout the airport process as well as strengthen the security concerns and reduce the human error. Airport access controls, screening methods, travel documents (passport), E-gates, permit entrance to the sterile gates, identification in baggage claim, border control clearance process can improve based on the biometric readers and provide seamless service to the passenger.

Verify the identity of individual passengers prior to board in to aircraft in critically important to ensure safe air travel. Bio metric ravel documents can use to improve the accuracy levels to recognize individual passengers separately $(\mathrm{ACl}, 2005)$. This technology can easily verify that passengers' board in to the aircraft are the same individual who checked-in as per the procedures. At the check-in point can take the first biometrics such as finger prints and facial reconditions to monitor the passengers by using intelligent CCTV's and border control will cross check the accuracy with passenger travel document. Then passengers can easily access to the boarding gate with smart boarding pass and biometric proof. Most of the modern airports already adopted this methodology to improve passenger convenience, process efficiency, reduce manpower involvement, and improve accuracy levels and feeding data to use Al decision makings.

\section{e) Smart wearable}

With modern technology wearable hardware solutions are in use and embedded micro system is the core structure. Physical interaction module share environmental sensors to measure temperature and humidity, scanners and remote controller modules. Passenger centric modules operate touch screens, cameras, audio features and motion sensors. Communication systems include WiFi, Bluetooth, GPRS, IOT \& other latest communication methods (Kong, Luo, Huang, \& Yang, 2019). Smart devices such as watches, electronic hand bands, Bluetooth hats, smart glasses, head phones and electronic accessories with sensors use to give alerts to passengers on timing for airport formalities. Further, they are being informed on boarding gate changes, check-in counter, special discounts in duty-free shops and restaurants and more passenger convenience. Real-time travel information starts from the front door of the terminal or at the taxing of the aircraft for arriving passengers. 


\section{f) RFID baggage tags}

The radio frequency identification (RFID) technology mainly use for baggage handling process. This technology facilitate to monitor the screening remotely from the particular location with several interfaces. Passengers will be benefitted from RFID baggage tags to trace their baggage, status of baggage loading or unloading to the aircraft during their departure, arrival or transit (Kovynyov \& Mikut, 2018). Smart airports can reduce the risk of mishandle baggage by using this technology. Additional data can be added in to the system such as manufacturer, brand and the size of the baggage. Human involvement is very less and explosive detection system may reduce the risk of damages to happen.

\section{g) Self-baggage tagging}

There is a growth of full service and low cost carriers and self-connecting air passengers will increase in Asia similar to European airports. Major Asian hubs such as Singapore, Tokyo Narita, Kuala Lumpur, and Seoul Incheon airports will be the key self-handling airports to handle their rapid growth of passengers (Chang, Lee, \& Wu, 2019). Smart Airports facilitate passengers to tag their own baggage by using baggage drop-off machines at the departure terminal. Passengers can print their baggage tag from their house and most of the budget airlines prefer this methodology to reduce their stationary and operational cost. The same time can track the baggage status through the smart phone. Digital baggage tags are an alternative to conventional paper-based baggage tags. Given digital barcode can be changed remotely by airlines or ground handling agents in case of changes of the flight or off-load plan.

h) Kiosks for Lost Luggage

RFID technology can adopt in to the lost luggage problem and this system distribute baggage to the correct loading aircraft and allowing passenger to monitor throughout the transit and at the arrival (Shehieb et al., 2017). Kiosks for Lost Luggage are connected to the global airline \& airport network and help passengers to trace the status of their baggage via smart mobile phone. Reporting lost luggage system also easing by allowing passengers to scan the boarding pass and include brief on the items were in packed in the luggage and forward to the relevant airline. In the same message or email can include the present contact details of the passenger and address for the delivery of the luggage found.

\section{i) Border control}

Clearance form regulatory agencies such as Immigration \& Emigration, Customs, Intelligent services and quarantine are required to complete the full authorization. Airport Council International recommends to use international standardized formats for biometric data and introduce harmonized approach for the same
(ACl World, 2005). Automated border control systems not having required control over the facial recognition and additional security measures required to check the accuracy between travelling person and travel document. Therefore it is required to introduced biometric readers in addition to the facial recognition to the e-gates located at border controlling points (Sanchez del Rio, Moctezuma, Conde, Martin de Diego, \& Cabello, 2016). E-gate systems can be introduced for both departure and arriving passengers. In addition to the airport infrastructure, regulatory border control body of the country should initiate the electronic travel documents for the use of local citizens at the initial stage.

\section{j) Airport Apps for Mobile Devices}

Passengers can have airport services through mobile applications and Ticket Kiosks on their booking completion through the travel agent or online portal of the airline. In generally SMART airport experience starts 48 hours prior to the departure. After providing itinerary details this application starts to work and assist the passenger with all features available (Harteveldt, 2016).

The primary options of the smart airport mobile application activate with the itinerary details such as luggage pick up of the passenger from any given location. Then passengers need not carry the luggage along with him/her to the airport. A SMART application connected to cab services and passenger will be pick up from home and drop at the airport on time. Passengers will get continuous alerts \& reminders on flight status. Google Indoor map will assist indoor walking with directions to walk within the terminal.

Kiosks will validate the itinerary once a passenger collects the boarding pass and same time can change seating arrangement on their preference. After passenger verification, automated Kiosks will print baggage tags. Baggage will correctly be sent to the relevant feeding bay based on the RFID readers and passenger will get updates to their smart mobile phone at feeding bay, carrying to the aircraft and after the baggage loaded to the aircraft(Abdullah Alghadeir, 2016).

After the baggage dumping, the application guide passenger through other formalities such as security check and immigration with specific distance and waiting time. If sufficient time available to the boarding, passengers may get some special Duty Free shop promotions into their mobiles as a promotional tool to improve airport revenue. Further, the application shows restaurants, washrooms, smoking zone, lounges and other facilities available for their waiting time. All relevant public announcements come to the mobile phone in both voice recording and text. Once the aircraft is ready for boarding passenger should just scan the boarding pass at the gate and RFID scanning screener 
will open the gate at the boarding as well as the boarding bridge up to the aircraft door.

\section{Strategic Challenges}

\section{a) Cyber Security}

The key risk factor of Smart Airport is Cyber security and it is one of the most critical safety factor need more attention in modern airport operation. To provide optimal services in reliable \& sustainable manner, smart airports struggle with growth, efficiency, safety and security (Lykou, Anagnostopoulou, \& Gritzalis, 2019). The modern SMART application process which is open for open data and big data is clearly open for cyber-attacks as these systems are working independently. In addition to that, system access permitted through dedicated APIs to have innovations and developments generate the unwanted risk of cyberattacks. Data interception, access to local network, interferences to data transferring and denial of service are the key risks of smart airport technological adaptation. Accessing to confidential data of the passengers by unauthorised persons may challenge to the privacy of them.

Cyber security treats are emerging in addition to the physical security of an airport as the increase of technological adaptation specially with mobile based applications created for passenger convenience. Smart airports may have high tech communication equipment and related infrastructure to support sophisticated aircraft technology and navigational systems to maintain effective end to end communication via different applications. Therefore the cyber security risk is further increasing and mitigation actions need to be taken on priority basis (Gopalakrishnan, Govindarasu, W. Jacobson, \& M. Phares, 2013). Therefore it is necessary to establish Cyber-attack detection centres internally or outsource the requirement. Further, penetration tests need to be carried out continuously in the same model.

As risk mitigating strategies should implement industry standards among all the users of smart airport systems, introduce cyber security measures, and educate both technical personnel and users. Educational campaigns more effective if conduct on the user focused method to provide customised knowledge to prevent cyber security risks and recommended to the airport staff who assign to monitor the system.

\section{b) Return on "Smart" Investment}

It is difficult to manage fixed and moveable resources of an airport effectively, as they have to spend largely on capital expenditure which is not properly managed. Cloud technology can be used for reducing IT-related hardware cost and manpower cost involvement. Heavy capital investments required for smart airport technology as traditional technology and infrastructure not capable to ful fil the requirement. Therefore advanced technology applications must focus on cost involvement against the efficiency level improvements. The latest Airport 4.0 technology use for smart airports such as big data analysis, Internet of Things and augmented reality should apply to enhance the efficiency level of the airport operations in addition to the passenger facilitation.

Kansai Airport is keen on energy saving and planning to use hydrogen and clean energy for their terminal development (Baxter, Srisaeng, \& Wild, 2018). Energy consumption including illumination and aircondition for terminal buildings can control based on intelligent CCTVs and automated controllers based on passenger traffic. Most of the businesses use traditional KPI's to measure the performance focus on physical capital or human capital such as inventory, productivity and utilization. Digital transformation not affect to the basic KPI's of the company and need to track intermediate indicators (Barry Libert, Beck, \& Wind, 2016).

Though the initial introduction cost is high in technological adaptation in long run will generate more profits against the investment. It is recommended to invest on smart features on priority basis by identifying most critical elements and data integration requirements. Digital transformation cost of smart airports can be handled carefully and cost saving methods should be introduced systematically. Above decisions should be taken based on dynamic manner. Financially viable projects should be implemented by considering the ROI. User-friendly semi-technology should be adopted in several development stages whilst educating the internal \& external agencies of the airport operation and slowly adopt passengers also into this. Digital transformation cannot run overnight and should be in rationalised approached on identified priorities.

\section{c) Change the Mind-set and Maintain Standards}

As per the Technical Acceptance (TAM) when people have a positive attitude towards something they form intention to perform behaviours whilst technological adoption in different industries is being explained with the said model (Davis, Bagozzi, Bagozzi, \& Wars haw, 1989; Nayanajith, \& Dissanayake, 2019). Technology can reshape the business models of provided stakeholders adopt it (Siriwardane \& Dissanayake, 2018). Therefore the airport operator should maintain positive attitude of airport employees on technical adaptation and closely coordinate with relevant stakeholders including regulatory agencies, airlines and other related institutions. Airports should identify, prioritize and implement required digital solutions which are specifically relevant to the context of airport operations. This may be challenged by non-digitalized mind-set within the organization. It is required to change the mind-set of airport staff including regulatory agencies as well as concessionaries. They may have required training on how to operate their own systems 
and educate on basic features and importance of the system implementation. It is required to have the relevant technological knowledge and maintain the standards of systems up to the industry requirements.

\section{Conclusion}

Smart airport concept is the future of the airport operations. There are some key operational areas identified in the passenger terminal process to introduce digital transformation as passenger operations, baggage handling and border control by regulatory agencies. Major components in implementing the smart airport functions are Aviation security, Passenger convenience, Operational efficiency and Optimizing limited resources. Each factor is easing the process with comfortable and effective operation with modern technology adaptation such as RFID Screening, IoT, Big data analysis and other features of digital transformation. Smart Check-in, Self-boarding, Indoor navigation, Biometric services, Using smart wearable, RFID baggage tags, Self-baggage tagging, Kiosks for Lost Luggage, Border control and Airport Apps for Mobile Devices can identify as application tools of the smart airport concept. Need special attention on key strategic challenges to implement the smart airport operation. Cyber security is the most vulnerable threat to smart features of any airport and special controls need to be introduced. The digital transformation is a costly exercise and return of the intended investment should be considered (Rassool \& Dissanayake, 2019). Airport staff should be trained properly to create a positive approach on digital transformation together with all regulatory \& supportive agencies. Future researches recommended to identify the required level of smart technology adaptation in airport operations subject to the return on investment. Special attention on specific regional studies may give more accurate research findings to determine the most relevant smart airport adaptation levels. Conclusively, future research works need more attention to provide practise related insights on how to model smart airport concept specially in emerging economies and tourism sector focused countries. Such infrastructure developments result direct and indirect impact on connected industries.

\section{References Références Referencias}

1. Abdullah Alghadeir, H. A.-S. (2016). Smart Airport Architecture Using Internet of Things. International Journal of Innovative Research in Computer Science \& Technology (IJIRCST), 4(5), 148-155.

2. ACl World. (2005). the Application of Biometrics at Airports. 16. Retrieved from http://www.aci.aero/Me dia/aci/file/Free docs/ACl Biometric Position FINAL.pdf

3. ACl World. (2019). Preliminary world airport traffic rankings released - ACI World. Retrieved December
17, 2019, from https://aci.aero/news/2019/03/ 3/preliminary-world-airport-traffic-rankings-released/

4. Al Nuaimi, E., Al Neyadi, H., Mohamed, N., \& AlJaroodi, J. (2015). Applications of big data to smart cities. Journal of Internet Services and Applications, 6(1), 25. https://doi.org/10.1186/s13174-015-0041-5

5. Almashari, R., Aljurbua, G., Alhoshan, L., Al Saud, N. S., Binsaeed, O., \& Nasser, N. (2018). loT-based Smart Airport Solution. 2018 International Conference on Smart Applications, Communications and Networking, Smart Nets 2018, 1-6. https://doi.org/10.1109/SMARTNETS.2018.87 07393

6. Barry Libert, by, Beck, M., \& Wind, Y. (2016). Reprint H0308q Published on Hbr.Org Article Change Management 7 Questions to Ask Before Your Next Digital Transformation.

7. Baxter, G., Srisaeng, P., \& Wild, G. (2018). Sustainable Airport Energy Management: the Case of Kansai International Airport. International Journal for Traffic and Transport Engineering, 8(3), 334-358. https://doi.org/10.7708/ijtte.2018.8(3).07

8. Bouyakoub, S., Belkhir, A., Guebli, W., \& Bouyakoub, F. M. hame. (2017). Smart airport: An loT-based Airport Management System. ACM International Conference Proceeding Series, Part F1305. https://doi.org/10.1145/3102304.3105572

9. Castillo-Manzano, J. I., \& López-Valpuesta, L. (2013). Check-in services and passenger behaviour: Self service technologies in airport systems. Computers in Human Behavior, 29(6), 2431-2437. https://doi.org/10.1016/j.chb.2013.05.030

10. Chang, Y. C., Lee, W. H., \& Wu, C. H. (2019). Potential opportunities for Asian airports to develop self-connecting passenger markets. Journal of Air Transport Management, 77, 7-16. https://doi.org /10.1016/j.jairtraman.2019.02.001

11. Changiairport.com. (2019). FAST transformation @Changi Airport | Changi Airport Group. Retrieved December 17, 2019, from http://www.changiai rport.com/corporate/media-centre/resourcees/p ublication/issue-4/fast-changi.html

12. Cheng, S. W., Zhang, Y. P., \& Guo, Y. Y. (2012). Theory of Allocating and Scheduling Resources at Airport Passenger Terminals: A Review. Advanced Engineering Forum, 5, 66-70. https://doi.org/10 .4028/www.scientific.net/aef.5.66

13. Davis, F. D., Bagozzi, R., Bagozzi, R. P., \& Warshaw, P. R. (1989). User Acceptance of Computer Technology: A Comparison of Two Theoretical Models Reshoring from a demand-side perspective View project household food waste minimization View project User Acceptance of Computer Technology: A Comparison of Two Theoretical Models User Acceptance of Computer Technology: A Comparison of two Theoretical 
Models*. Source: Management Science, 35(8), 982-1003. https://doi .org/10.1287/mnsc.35.8.982

14. Gopalakrishnan, K., Govindarasu, M., W. Jacobson, D., \& M. Phares, B. (2013). Cyber Security for Airports. International Journal for Traffic and Transport Engineering, 3(4), 365-376. https://doi. org/10.7708/ijtte.2013.3(4).02

15. Gayan Nayanajith, D. A. \& Dissanayake, D. M. R. (2019) "E-Banking Adoption in the Context of Innovation and E-Service Quality: A Review on Concepts and Practices", Journal of Environmental Science, Computer Science and Engineering \& Technology, Vol.8 Issue:3, pp.208-221, https://do i.org/10.1108/0265232031045777 6

16. Harteveldt, H. H. (2016). The Future of Airline Distribution, 2016-2021.

17. IATA. (2019). IATA - Asia Pacific 20 Year Forecast. Retrieved December 17, 2019, from https://www.ia ta.org/about/worldwide/asia_pacific/Pages/AsiaPacific-20-Year-Forecast.aspx

18. Incheon Airport. (2019). Connecting People and Incheon Airport.

19. Jalali, R., \& Zeinali, S. (2018). Smart Flight Security in Airport Using IOT (Case Study: Airport of Birjand). International Journal of Computer Science and Software Engineering, 7(6), 142-147. Retrieved from https://search. proquest.com/docview/2084838874? accountid=134127\%0Ahttp://link. periodicos.capes. gov.br/sfxlcl41?url_ver=Z39.88-2004\&rft_val_fmt= info:ofi/fmt:kev:mtx: journal\&genre $=$ unknown $\&$ sid $=$ ProQ:ProQ\%3Ahightechjournals\&atitle=Smart+Flig ht + Security+in+Airp

20. Kong, X. T. R., Luo, H., Huang, G. Q., \& Yang, X. (2019). Industrial wearable system: the humancentric empowering technology in Industry 4.0. Journal of Intelligent Manufacturing, 30(8), 28532869. https://doi.org/10.1007/s10845-018-1416-9

21. Kovynyov, I., \& Mikut, R. (2018). Digital Transformation in Airport Ground Operations. Retrieved from https://www.researchgate.net/pu blication/325333250_Digital_Transformation_in_Airp ort_Ground_Operations

22. Lee, S., \& Miller, S. (2019). Distilling managerial insights and lessons from Al projects at Singapore' s Changi Airport ( Part 2 ). (Part 2), 1-6.

23. Lykou, G., Anagnostopoulou, A., \& Gritzalis, D. (2019). Smart airport cybersecurity: Threat mitigation and cyber resilience controls. Sensors (Switzerland), 19(1). https://doi.org/10.3390/s1 9010019

24. Mantouka, E. G., Barmpounakis, E. N., Milioti, C. P., \& Vlahogianni, E. I. (2019). Gamification in mobile applications: The case of airports. Journal of Intelligent Transportation Systems: Technology, Planning, and Operations, Vol. 23, pp. 417-426. https://doi.org/10.1080/15472450.2018.1473157
25. Medvedev, A., Alomar, I., \& Augustyn, S. (2017). Innovation in airport design. Aviation, 21(1), 23-28. https://doi.org/10.3846/16487788.2017.1303542

26. Mohamed, M., Gomaa, H., \& El-Sherif, N. (2018). Exploring the Potentiality of Applying Smart Airport Technologies in Egyptian International Airports. International Journal of Heritage, Tourism and Hospitality, 12(2), 122-129. https://doi.org/10.216 08/ijh th.2019.31984

27. Munich Airport. (2019). Security screening smoother than ever - Munich Airport. Retrieved December 17, 2019, from https://www.munichairport.com/the-quickest-way-to-your-gate-6081651

28. Nagy, E., \& Csiszár, C. (2016). Airport Smartness Index - evaluation method of airport information services. (Dezembro).

29. NATS. (2019). Transforming the Airport Experience: The Future of Smart Airports - NATS. Retrieved December 17, 2019, from https://www.nats.ae ro/apac/august-enewsletter/transforming-airportexperience-future-smart-airports/

30. Nau, J.-B., \& Benoit, F. (2017). SMART AIRPORT HOW TECHNOLOGY IS SHAPING THE FUTURE OF AIRPORTS. Retrieved from www.wavestone.com

31. Qi, Q., \& Pan, Z. (2018). Internet of Things, Internet, Big Data and Airport Services Make Smart Airport Based on $\mathrm{O} 2 \mathrm{O}$ and Humanism. 149(Mecae), 134137. https://doi.org/10.2991/mecae-18.2018.30

32. Rassool,M.P.R. \& Dissanayake,D.M.R. (2019). Digital Transformation For Small \& Medium Enterprises (SMEs): With Special Focus On Sri Lankan Context As An Emerging Economy, International Journal of Business and Management Review Vol.7, No.4, pp.59-76

33. Sabatová, J., Galanda, J., Adamčík, F., Jezný, M., \& Šulej, R. (2016). Modern Trends in Airport Self Check-in Kiosks. MAD - Magazine of Aviation Development, 4(20), 10. https://doi.org/10.14 311/mad.2016.20.02

34. Sanchez del Rio, J., Moctezuma, D., Conde, C., Martin de Diego, I., \& Cabello, E. (2016). Automated border control e-gates and facial recognition systems. Computers and Security, 62, 49-72. https://doi.org/10.1016/j.cose.2016.07.001

35. Sharif, M., Raza, M., Shah, J. H., Yasmin, M., \& Fernandes, S. L. (2019). An Overview of Biometrics Methods. In Handbook of Multimedia Information Security: Techniques and Applications (pp. 15-35). https://doi.org/10.1007/978-3-030-15887-3_2

36. Shehieb, W., Al Sayed, H., Akil, M. M., Turkman, M., Sarraj, M. A., \& Mir, M. (2017). A smart system to minimize mishandled luggage at airports. PIC 2016 -Proceedings of the 2016 IEEE International Conference on Progress in Informatics and Computing, 154-158. https://doi.org/10.1109/PIC.2 016.7949485 
37. Siriwardana, A. \& Dissanayake, D.M.R. (2018). Social Customer Relationship Management (SCRM) in Contemporary Business Era, International Journal Business and Management Invention (IJBMI),7(9), 59-64

38. Skytrax. (2019). World's Top 10 Airports 2019 | SKYTRAX. Retrieved December 17, 2019, from https://www.worldairportawards.com/worlds-top-10airports-2019/

39. Wittmer, A. (2011). Acceptance of self-service check-in at Zurich airport. Research in Transportation Business and Management, 1(1), 136-143. https://doi.org/10.1016/j.rtbm.2011.06.001 